\title{
Differential repetition of common versus uncommon word associations ${ }^{1,2}$
}

\author{
JOHN R. BRAUN, ARTHUR CONSTANTINI, ${ }^{3}$ JAMES LINK, ${ }^{4}$ AND BARBARA J. EHMER 5 \\ UNIVERSITY OF BRIDGEPORT
}

The tendency to repeat common versus uncommon word associations was investigated using 127 Ss. Each had two administrations of a 100-word association list, with $86 \mathrm{Ss}$ instructed on their second administration to repeat the responses made originally, and with $41 \mathrm{Ss}$ not specifically instructed to repeat. For both groups, the mean number of common associations repeated was significantly greater than the mean number of uncommon associations.

Maltzman (1960) studied the problem of originality from an S-R framework. He found that presenting a word association list a number of times with instructions to give a different response on each presentation results in the production of less common associations on both the original list and on a new list. This increase and transfer of originality was explained as follows. Reinforcement was present in the situation since "The mere occurrence of a connection strengthens it" (Thorndike, 1949, p. 23). Differential reinforcement of uncommon versus common associations took place because "...the amount of reinforcement is inversely related to the initial probability of a verbal stimulus evoking a verbal response. Originality is more reinforcing than commonplace responding." (Maltzman, 1960).

The present study tested the Maltzman hypothesis by comparing the tendency to repeat common versus uncommon word associations. It was reasoned that if giving an original response is more reinforcing than giving a common response, then Ss should be more likely to repeat their uncommon than their common associations.

\section{Method}

Subjects were 127 university students enrolled in undergraduate psychology classes. All data were gathered in regular class meetings. The procedure involved two administrations of a 100 word list presented in booklet form. Words included in the list were selected at random from the 200 word list of Palermo \& Jenkins (1964). First administration instructions called for $S$ to write next to each word the first word of which it made him think.

Two groups of Ss were used. One group $(\mathrm{N}=86)$ had a two day interval between administrations, and was specifically instructed on the second test to try to write the same responses originally made. The second group $(N=41)$ had a one week interval and instructions for the retest acknowledged that this was the second time $S$ had responded in the situation, but stressed that the responses were to be "free." Thus for this group there were no specific instruc- tions to repeat the associations given on the first occasion. These second group instructions were patterned after those used by Hall (1966).

Data were analyzed as follows. For each $S$, the commonness of each of his first occasion associations was determined by reference to the normative data provided by Palermo \& Jenkins (1964). Likewise for each $S$, the 50 responses which were most common according to the normative data were designated as "common," while the remaining 50 responses were designated as "uncommon." Second administration data were then examined to determine for each $\mathrm{S}$ whether he had repeated more of his common or his uncommon associations.

\section{Results and Discussion}

For the group instructed to try to repeat, the mean number of common associations repeated on the second administration was 38.66 , with $\mathrm{SD}=5.78$, while the mean number of uncommon associations repeated was 23.94, with $\mathrm{SD}=7.31$. For the group not specifically instructed to repeat, the mean number of common associations repeated was 32.73, $\mathrm{SD}=6.55$, and the mean number of uncommon associations repeated was $15.93, \mathrm{SD}=6.21$. For both groups, $t$ tests based on correlated data revealed that significantly more common than uncommon associations were repeated $(p<.001)$. The consistency of the finding is indicated by the fact that of the 127 Ss, 126 had greater repetition of their common as opposed to uncommon associations, while the remaining $S$ had exactly the same scores for the two categories. The findings are opposite to those predicted, and therefore provide no support for the Maltzman hypothesis that "Originality is more reinforcing than commonplace responding."

Our findings also have relevance to the study of reliability of free association responses made by Hall (1966). Hall found that neither the ThorndikeLorge frequency of the stimulus words nor the interval between sessions influenced the number of repetitions made by Ss. He reported that "... slightly less than $50 \%$ of the time an S's response to a stimulus word will be the same on the second testing as that provided on the first." The results with our Ss who were tested under conditions similar to those of Hall (no specific instructions to repeat) approximate the Hall finding closely. Our overall percentage of repetition was 48.66 . However, our findings demonstrate a variable that does influence the percentage of repetition-the commonness of the response ori- 
ginally made. The mean repetition percentage for common responses was $65.46(32.73 / 50)$, while the mean repetition percentage for uncommon responses was $31.86(15.93 / 50)$.

\section{References}

HALL, J. F. The reliability of free association tesponses. Psychon. Sci, $1966,4,79-80$.

HOUSTON, J. P., \& MEDNICK, S. A. Creativity and the need for novelty. J. abnorm, soc. Psychol, 1963, 66, 137-141.

MALTZMAN, I. On the training of originality. Psychol Rev., 1960, $67,229-242$.
PALERMO, D. S., \& JENKINS, J. J. Word association norms. Minneapolis: University of Minnesota Press, 1964.

THORNDIKE, E. L. Selected writings from a connectionist's psychology. New York: Appleton-Century Crofts, 1949.

Notes

1. This study was supported by a grant to the senior author from the University of Bridgeport Faculty Research Fund.

2. A report of the study was presented at the 1967 meeting of the Educational Research Association of New York State in Albany. 3. Now at Lyndon College.

4. Now with Dunlap and Associates; Darien, Connecticut.

5. Now at the University of Connecticut.

\section{A Comment on Acoustic Data and Recognition in Short-Term Memory by D. Marcer University of Southampton, England}

Pearthree, Gorfein, \& Bennett (1967) report a method for selecting alternatives to be used in STM recognition studies, and conclude from their data that factors other than the acoustic coding of items play an important role in short-term retention.

This conclusion is based largely on the finding that the mean score in their recognition experiment was 0.7657 correct recognitions, while the "spell" scores had a mean proportion of 0.2660 correct. It is suggested here that the difference could be an artifact of the way in which the two scores were obtained.

The spell scores were based on the number of correctly decoded responses compared with the total number of responses to that syllable by all Ss. The method of obtaining the spell score responses was to play back continuously the tape recording of S's verbalizations of the stimuli with instructions for $S$ to write each syllable as he decoded it from his pronunciation.

It seems reasonable to suggest that some form of recognition memory will be involved in this process. $\mathrm{S}$ will generate as many appropriate solutions as possible to the sound stimulus, and select the cor- rect response from this array. In fact, this process is implied in the recognition study, where the array presented to the $\mathrm{S}$ consisted of stimuli drawn from the spell data.

In their report of the spell score experiment the authors do not give details of the interstimulus presentation time. However, their report that the tape played back continuously suggests it was short. If so, the possibility of $\mathrm{S}$ being able to generate all possible solutions to the verbalized stimulus, and then select his response would be greatly restricted. This would be especially so when compared with the recognition experiment, where solutions were presented to $S$, leaving the whole $10.5 \mathrm{sec}$ recall period free for the selection of the appropriate response. It would be expected, therefore, that recognition scores would be greater than those obtained by the spell group, where $S$ might not have time to include the correct response in his self-generated array from which a single response is made.

\section{Reference}

PEARTHREE V., GORFEIN D. S., \& BENNETT R. W. Acoustic data and recognition in short-term-memory, Psychon. Sci., 1967, 8, 59-60. 